\title{
SEGUIMOS DISCUTIENDO SOBRE PERMISOS Y CONCEPCIONES DEL DERECHO *
}

\author{
Juan Ruiz Manero \\ Universidad de Alicante
}

RESUMEN. En este trabajo, el autor replica al artículo de E. BULYGIN «Sobre la equivalencia pragmática entre permiso y no prohibición», que se publica en este mismo número de Doxa. Las críticas del autor a E. BULYGIN se pueden reconducir a estas dos: primero, la actitud de BULYGIN respecto a las creencias compartidas por los juristas implica ignorar que el Derecho pertenece a la categoría de los hechos institucionales; segundo, permiso positivo y no prohibición son pragmáticamente equivalentes en relación con la conducta objeto de la permisión expresa o de la no prohibición; para poder dar cuenta de las diferencias pragmáticas entre diversos tipos de permisos hay que introducir las distinciones entre permisos prima facie y permisos concluyentes y entre permisos no protegidos y permisos protegidos.

Palabras clave: E. BuLYGIN, permisos fuertes, permisos débiles, permisos prima facie, permisos concluyentes, permisos protegidos, permisos no protegidos, lagunas en el Derecho.

ABSTRACT. In this paper, the author replies to the article by E. BULYGIN «On the Pragmatic Equivalence between Permission and Non-prohibition", published in this issue of Doxa. The criticism the author directs at E. BULYGIN can be summarized in these two points: firstly, BULYGIN's attitude with regard to beliefs shared by the legal community means ignoring that law belongs to the category of institutional facts, and secondly, positive permission and non-prohibition are pragmatically equivalent in relation to the behaviour which is the object of explicit permission or of non-prohibition; to be able to account for the pragmatic differences between various types of permissions we need to use the distinctions between prima facie permissions and conclusive permissions, and between unprotected permissions and protected permissions.

Keywords: E. BULYGIN, strong permissions, weak permissions, prima facie permissions, conclusive permissions, non-protected permissions, protected permissions, legal gaps.

* Fecha de recepción: 15 de abril de 2011. Fecha de aceptación: 9 de mayo de 2011. 
1.

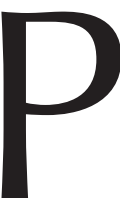

ocas cosas he hecho en mi vida profesional más estimulantes, en las que haya aprendido tanto y de las que haya disfrutado más que discutir con E. BuLYGIN. En una conversación con M. ATIENZA que nuestros compañeros de Alicante juzgaron en general algo impúdica y que publicamos hace algo más de un año ${ }^{1}$, tuve ocasión de señalar que llevaba veinte años discutiendo con Eugenio y que no excluía la posibilidad de nuevos rounds. Y hete aquí que el trabajo de Eugenio que se publica en este mismo número de Doxa — «Sobre la equivalencia pragmática entre permiso y no prohibición»- viene a iniciar y a exigir este nuevo round. Y, por lo que acabo de decir, se comprenderá que ello me sitúa en la poco lamentable posición de aquel que actuaría mal, y daría pie a críticas justificadas, si no hiciera aquello que le gusta hacer, aquello que le estimula, de lo que aprende y que le hace disfrutar. O sea, replicar, una vez más, a Eugenio.

Pues bien: a lo largo de mis discusiones con Eugenio he tenido ocasión de aludir a dos rasgos generales de su teoría del Derecho que, a mi juicio, muestran la inadecuación de la orientación, asimismo general, de la misma. El primero de estos rasgos es la incapacidad de la teoría del Derecho de Eugenio para dar cuenta de las controversias entre los juristas, relativas a cuál sea la solución jurídicamente correcta de unos u otros casos, genéricos o individuales. Pues, a juicio de Eugenio, no hay, a este respecto, controversias jurídicas genuinas: el Derecho, en aquellos supuestos en que no determina incontrovertiblemente la solución para el caso, concede discreción para optar entre soluciones que vienen a ser todas ellas equivalentes en cuanto a su justificación jurídica; las discrepancias en torno a ellas no serían sino expresiones de distintas preferencias personales ajenas al Derecho. Discutir lo que el Derecho exige en relación con un cierto caso sería, de este modo, una empresa intelectual sencillamente equivocada de raíz. Pues, o no hay nada que discutir porque el Derecho contiene una solución incontrovertible para el caso o no hay nada que discutir porque es incontrovertible que el Derecho no contiene una solución para el caso, sino varias y que, para elegir entre ellas, el mismo Derecho no proporciona guía alguna. Lo primero - que el Derecho contenga una solución incontrovertible para el caso- ocurre si el Derecho contiene una regla en la que subsumir el caso; lo segundo — que sea incontrovertible que el Derecho no contiene una solución para el caso y que el operador tiene discreción para elegir, en forma no guiada por el Derecho, entre varias soluciones con el mismo grado de justificación jurídica - ocurre en los supuestos de laguna normativa, de antinomia y de laguna de reconocimiento ${ }^{2}$. Una parte bien sustancial del discurso de los juristas obedecería, así, a un puro malentendido y debería arrojarse, como tal, al basurero de los sinsentidos. Y otro tanto cabría decir de los metadiscursos que, como la teoría de la argumentación jurídica, tratan de ofrecer pautas que guíen ese discurso de los juristas.

1 «A modo de epílogo: Una conversación sobre teoría del Derecho y otras varias cosas», en M. ATIENZA y J. Ruiz Manero, Para una teoría postpositivista del Derecho, Lima-Bogotá, Palestra-Temis, 2009.

2 Un exposición y crítica de las diferentes modalidades de relación entre casos y normas en la teoría de Bulygin (y AlchourRón) puede verse en J. Ruiz MANERO, «Algunas concepciones del Derecho y sus lagunas», en F. Atria, E. Bulygin, J. J. Moreso, P. Navarro, J. RodrígueZ y J. Ruiz Manero, Lagunas en el Derecho. Una controversia sobre el Derecho y la función judicial, Madrid-Barcelona, Marcial Pons, 2005. 
El segundo de los rasgos generales de la teoría del Derecho de Eugenio al que hacía referencia viene a consistir en aquello que justifica al primero de estos dos rasgos: pues la creencia de los juristas en que hay discrepancias jurídicas genuinas, en que, cuando ellos mismos discuten cuál es la solución correcta de un caso, están discutiendo acerca de lo que el Derecho exige para ese caso y no meramente exhibiendo sus preferencias personales, no es la única creencia de los juristas que no debemos tomar en serio. Las creencias compartidas por los juristas no determinan de ningún modo, de acuerdo con Eugenio, cómo sea el Derecho y pueden estar por ello completamente equivocadas: tan equivocadas como las de los químicos (o los alquimistas) acerca de la composición de un trozo de materia o las de los biólogos (o los teólogos) acerca de laevolución de las especies. En este sentido Eugenio ha señalado enfáticamente, replicando a C. REDONDO, que le tiene «sin cuidado» alejarse «de la autocomprensión que los participantes tienen del Derecho», pues éstos «no son infalibles y sus creencias son, a veces, profundamente equivocadas» ${ }^{3}$ y ha indicado también, refiriéndose a mí, que «mi amigo Juan está levemente equivocado en algunos puntos centrales de la teoría jurídica» y que le parece «especialmente pernicioso» mi supuesto «apego a las creencias de los juristas, que suelen ser muy equivocadas» ${ }^{4}$.

Este desprecio de Eugenio por las creencias compartidas por los juristas involucra, a mi modo de ver, una incomprensión grave del tipo de realidad que el Derecho es, o si se prefiere, de la región ontológica en la que se sitúa el Derecho, que no es la de los hechos brutos, por completo independientes de las creencias de los observadores, sino la de los hechos institucionales, cuya existencia depende de creencias y actitudes compartidas. Y es que el Derecho es algo que depende, enteramente, de la aceptación colectiva; primariamente, de la aceptación por parte de los jueces y tribunales en su conjunto de las normas que exhiban ciertas características como normas que deben constituir el fundamento de sus resoluciones; secundaria o derivadamente, de esa misma aceptación — que puede ser en algunos casos mera simulación de aceptación — por parte del conjunto de la comunidad jurídica: esto es, por parte de quienes — como los abogados - operan ante jueces y tribunales dirigiéndoles demandas u oponiéndose a ellas en relación con casos individuales y también por parte de quienes - como los juristas teóricos, los cultivadores de la dogmática jurídica-operan como intermediarios entre las emisiones normativas en bruto de las autoridades a las que los tribunales se consideran vinculados y los tribunales mismos, transformando esas emisiones normativas en el sentido de dotarlas de mayor potencia resolutiva de casos (solucionando las antinomias e integrando las lagunas normativas que esas emisiones normativas puedan presentar) y de mayor coherencia de valores y de propósitos (solucionando los desajustes y lagunas axiológicas que puedan contener y, en general, mediante las tareas de interpretación y de sistematización).

De esta forma, las creencias centrales del conjunto de la comunidad jurídica - creencias centrales de las que forman parte, por ejemplo, el núcleo central de los criterios últimos de validez jurídica o el núcleo central de los criterios últimos de interpretación — no pueden estar equivocadas. Y la razón de que no puedan estar equivocadas

3 E. Bulygin, «María Cristina Redondo sobre distintos tipos de positivismo», en J. J. Moreso y M. ${ }^{a}$ C. ReDONDO, Un diálogo con la teoría del Derecho de Eugenio Bulygin, Madrid-Barcelona, Marcial Pons, 2007, 203.

${ }^{4}$ E. BuLYgin, «Un balance de mi relación intelectual con Juan Ruiz Manero», en $i d ., 187$. 
no es, naturalmente, que la comunidad jurídica sea, a este respecto, infalible. La razón de que tales creencias no puedan estar equivocadas es la misma que hace que tales creencias tampoco puedan ser verdaderas, esto es, que tales creencias no describen una realidad ajena a ellas mismas, con la que puedan ajustar o no, sino que esas creencias, y las correspondientes actitudes asimismo compartidas son constitutivas de esa realidad institucional a la que llamamos Derecho.

\section{2.}

No encuentro en el texto de Eugenio, «Sobre la equivalencia pragmática entre permiso y no prohibición», nada que me haga apartarme de la consideración de que, en materia de permisos, hay un par de distinciones de bastante mayor relevancia de la que media entre permisos positivos (o fuertes) y no-prohibiciones (o permisos negativos, o débiles). Estas dos distinciones, a mi juicio más importantes, son, por un lado, la que media entre permisos prima facie (sean positivos o negativos) y permisos concluyentes o definitivos y, por otro, la que media entre permisos no-protegidos y permisos protegidos.

En cuanto a la distinción entre permisos positivos (o fuertes) y negativos (o débiles) es obvio, me parece, que la situación de quien se dispone a realizar una determinada acción es, de entrada, la misma si esa acción está cubierta por una regla permisiva, referida tanto a su realización como a su omisión, que si esa acción meramente no está cubierta por una regla prohibitiva: en ambos casos la acción se encuentra normativamente disponible para él; pues el Derecho sólo arrebata la disponibilidad de una acción para su sujeto si califica la acción como obligatoria (con lo que prohíbe su omisión) o como prohibida. Y esto, por hipótesis, no ocurre tanto si el Derecho permite positivamente la realización y la omisión de la acción como si se limita a no prohibirlas (a permitirlas negativamente). Esta equivalencia pragmática para el sujeto de la acción entre el permiso positivo y la no prohibición es lo que hace que, en la mayor parte de los contextos ${ }^{5}$, el dictado de disposiciones permisivas carezca de sentido. Por poner un ejemplo trivial y muchas veces repetido: si la acción de ingerir zumo de naranja en el desayuno está disponible para mí, porque no hay ninguna regla que lo prohíba, ni que prohíba la omisión correspondiente, no se ve en qué cambiarían para mí las cosas si una autoridad normativa - digamos, el legislador- emitiera una disposición del tenor de «se permite tanto la ingesta como la no ingesta de zumo de naranja en el desayuno».

Por lo demás, tanto los permisos positivos contenidos en reglas como los permisos negativos derivados de la ausencia de reglas se asemejan entre sí en que ambos pueden verse desplazados por una regla prohibitiva en un juicio final que tenga en cuenta todas las circunstancias. $\mathrm{O}$, dicho de otra manera, ambos se asemejan en que se trata de permisos prima facie. En el caso de los permisos negativos este desplazamiento por una regla prohibitiva tiene lugar en virtud de la analogía: de la analogia legis si la emergencia en el juicio final de la regla prohibitiva se debe a que el caso no cubierto

5 Un examen de los contextos en los que tiene sentido el dictado de disposiciones permisivas se encuentra tanto en M. AtienZA y J. Ruiz MAnero, Las piezas del Derecho, Barcelona, Ariel, 4. ${ }^{a}$ ed., 2007, 128 y ss., como en J. Ruiz MANERO, «Algunas concepciones del Derecho y sus lagunas», cit., 119. 
por la regla prohibitiva comparte características tales con un caso cubierto por una regla prohibitiva que hacen que las razones para la prohibición que se aplican a este último caso se apliquen también, en un grado semejante (razonamiento a simili) o superior (razonamiento a fortiori), al caso no cubierto por regla alguna. En el caso de los permisos positivos este desplazamiento tiene lugar mediante las figuras del abuso del Derecho, el fraude de ley y la desviación de poder, que constituyen otros tantos mecanismos predispuestos para la derrotabilidad de reglas permisivas, cuando éstas se extienden hasta casos cuya permisión constituiría, de acuerdo con los propios principios del sistema, una anomalía valorativamente intolerable.

Es por estas razones por las que la distinción entre permisos prima facie y permisos concluyentes o definitivos me parece más importante que la distinción entre permisos fuertes y permisos débiles. Pues todos los permisos prima facie, tanto si se trata de permisos fuertes como de permisos débiles operan en el razonamiento jurídico aplicativo como meros ingredientes de un proceso deliberativo ${ }^{6}$ que desemboca en la construcción de la premisa normativa ${ }^{7}$ en la que subsumir el caso individual, en tanto que los permisos concluyentes operan como tal premisa normativa que fundamenta la resolución del caso individual.

Naturalmente, el carácter prima facie de los permisos contenidos en reglas y de los permisos derivados de la ausencia de reglas sólo es tal en algunos sectores del Derecho: en general, en todo el ámbito del Derecho privado. En otros sectores del Derecho —el Derecho penal, el Derecho administrativo sancionador - no hay distinción entre permisos prima facie y permisos concluyentes. Todo lo que en estos sectores del Derecho está permitido en el nivel de las reglas predispuestas - tanto si la permisión es fuerte como si es débil- resulta estar concluyentemente permitido. En estos sectores del Derecho, la distinción entre prima facie y concluyente opera únicamente en el sentido de excepcionar en el nivel concluyente prohibiciones contenidas en las reglas predispuestas, que resultan ser, así, prohibiciones sólo prima facie, pero no en el sentido de excepcionar en el nivel concluyente las permisiones, tanto fuertes como débiles, contenidas en las reglas predispuestas. Tales permisiones son, en estos sectores del Derecho, concluyentes o definitivas. Y, a este respecto, una vez más, tanto da que se trate de permisiones fuertes como de permisiones débiles.

3.

La equivalencia pragmática entre el permiso fuerte (o positivo) y el permiso débil (o no prohibición) aparece predicada exclusivamente, en el artículo mío al que hace referencia Eugenio ${ }^{8}$, de la acción que aparece, bien modalizada deónticamente

6 Al hablar de «proceso deliberativo» tengo presente lo que podríamos llamar una reconstrucción conceptual del razonamiento judicial; este «proceso deliberativo» no tiene por qué darse —y probablemente no se da-, como proceso psicológico, en los llamados casos fáciles.

7 Tal premisa normativa puede, eventualmente, expresarse mediante la misma formulación normativa que expresa una regla predispuesta que ha operado como ingrediente del proceso deliberativo; con la importante diferencia de que esa misma formulación normativa expresa en el primer caso una norma inderrotable y en el segundo — con la salvedad que se indica a continuación — una norma derrotable.

8 «Algunas concepciones del Derecho y sus lagunas», cit. 
como permitida, bien no modalizada deónticamente como prohibida. Y, en relación con dicha acción, tal equivalencia pragmática resulta indiscutible y no es, de hecho, discutida por Eugenio. Cuestión distinta es la de si la distinción entre permisos fuertes y débiles es o no pragmáticamente relevante en relación con acciones distintas, pero relacionadas con la acción permitida positiva o negativamente: esto es, en relación con acciones de interferencia (de impedimento o de prohibición, señaladamente) con aquella acción. Pues bien: a mi juicio, la distinción ahora relevante no es tanto la que media entre permisos fuertes y débiles como la que media entre permisos protegidos y permisos no-protegidos. Entiendo por permiso protegido aquel en el que la permisión va acompañada de una norma prohibitiva de acciones de interferencia y por permiso no protegido aquel en el que la permisión no se ve acompañada de una norma prohibitiva semejante $^{9}$. A mi modo de ver, el que un permiso sea fuerte es condición necesaria, pero no suficiente, de que se trate de un permiso protegido; tan sólo es condición suficiente, en un contexto de autoridades jerarquizadas, en relación con dictados por las autoridades superiores y en relación con ciertas acciones de interferencia por parte de las autoridades subordinadas, pero no en relación con otras posibles acciones de interferencia realizadas por otros sujetos; en otros contextos, y para otras acciones, el paso del permiso no-protegido al permiso protegido exige el concurso de la presencia como tal de la norma prohibitiva de la acción de interferencia.

Comprendo que todo esto, enunciado así, pueda parecer más bien misterioso, pero confío en que resulte claro mediante un ejemplo. Yo, que soy profesor de la Universidad de Alicante, disfruto del permiso de sentarme en los bancos que están distribuidos a lo largo del campus. Se trata de un permiso débil — no hay ninguna norma que se refiera a la acción de sentarse en los bancos- y no-protegido (sólo puedo usar mi permiso de sentarme en un banco si hay un hueco libre en el mismo; nadie que se haya sentado previamente tiene el deber de levantarse para que yo pueda sentarme). Supongamos que el permiso débil se transformara en permiso fuerte porque el Consejo de Gobierno de la Universidad dictara una disposición que dijera algo así como «todos los que se encuentren en el campus de la Universidad de Alicante tienen permiso para sentarse en los bancos que hay en él» (y, para que no surjan dificultades colaterales, supondremos que no hay, en esta materia, autoridades normativas subordinadas al Consejo de Gobierno de la Universidad). ¿Cambiaría algo las cosas el dictado de alguna disposición de este tipo? Me parece obvio que no. No las cambiaría en relación con la acción de sentarse - seguiría siendo una acción disponible que uno realiza si quiere y si hay huecos libres en el banco- ni tampoco en relación con la acción de levantarse para ceder el asiento a otro — - seguiría siendo asimismo una acción disponible que uno, si está previamente sentado, realiza si quiere-. Y precisamente porque no cambiaría las cosas ni en relación con la acción de sentarse ni en relación con la acción de levantarse para ceder el asiento, quizás el dictado de una disposición de este género sí cambiaría las cosas en relación con algo que aquí queda fuera de consideración: probablemente cambiaría la opinión colectiva sobre la salud mental de los miembros

9 Cfr. J. C. BAYÓN, «Sobre el principio de prohibición y las condiciones de verdad de las proposiciones normativas», en E. BuLYgin, M. ATIENZA y J. C. BAYÓN, Problemas lógicos en la teoría y la práctica del Derecho, Madrid, Fundación Coloquio Jurídico Europeo, 2009, 68 y ss.; cfr. asimismo L. HIERRO, «Conceptos jurídicos fundamentales: (I) De las modalidades deónticas a los conceptos de Derecho y deber», en Revista Jurídica de la Universidad Autónoma de Madrid, núm. 3, 2000, 156 y ss. 
de nuestro Consejo de Gobierno, asunto en el que pasaríamos de una prudente actitud de suspensión del juicio a pensar que no podía negarse que estábamos gobernados por un conjunto de perturbados. Imaginemos, ahora, que la permisión de sentarse en los bancos del campus es dictada, no por el Consejo de Gobierno de la Universidad de Alicante, sino por el legislador, en una eventual reforma de la legislación universitaria. Siendo las leyes jerárquicamente superiores a las normas dictadas por los Consejos de Gobierno de las universidades, parece que ahora sí han cambiado las cosas, en el siguiente sentido: dado que está prohibido a los órganos de producción normativa inferior dictar normas incompatibles con las dictadas por autoridades superiores, a nuestro Consejo de Gobierno le está prohibido dictar una norma que prohíba sentarse en los bancos del campus, así como establecer o aplicar sanciones como consecuencia de esa conducta (pues el establecimiento o la aplicación de sanciones implicaría considerar la conducta en cuestión como prohibida). El dictado, pues, de una norma permisiva por parte de una autoridad superior, ha protegido el permiso correspondiente frente a algunas acciones de interferencia con la acción permitida llevadas a cabo por algunos sujetos: las acciones, por parte de las autoridades inferiores, consistentes en prohibir la acción de sentarse en los bancos o en establecer o aplicar sanciones como consecuencia de ella.

Pero nótese que nuestro permiso no está protegido frente a todas las posibles acciones de interferencia: quiero decir que no lo está frente a aquella acción que no afecta a su status normativo, sino a su posibilidad de realización efectiva, esto es, frente a la acción consistente en impedir el uso del permiso por parte de otro permaneciendo uno sentado en el banco. Para proteger el permiso frente a esta acción de impedimento es preciso introducir una norma que estipule un deber —el de levantarse para ceder el asiento- frente al titular del permiso. Imaginemos una norma de este tipo, del tenor, por ejemplo de «si un profesor de la Universidad manifiesta su deseo de sentarse en un banco, todo no profesor sentado en él debe levantarse para cederle el asiento». La presencia de esta norma implica que la acción de sentarse en los bancos por parte de los profesores ya no constituye simplemente — en terminología hohfeldiana - un privilege o libertad frente a cualquiera, sino, además, un claim o Derecho subjetivo en sentido estricto frente a los no profesores —en esa misma terminología-.

\section{4.}

Examinemos ahora la posición de E. BuLYGIN en relación con los deberes del juez frente a una demanda que carece de fundamento normativo, porque se refiere a un caso en relación con el cual el Derecho no dispone nada. Aunque Eugenio no opera con la distinción entre lo que el Derecho dispone prima facie y lo que el Derecho dispone concluyentemente - para él, todo y sólo lo dispuesto prima facie está asimismo dispuesto concluyentemente- entenderé «el Derecho no dispone nada» en el sentido de «el Derecho no dispone nada concluyentemente». Pues bien: en un caso de este género, en un caso en el que el juez se enfrenta a una demanda que formula una pretensión respecto de la cual el Derecho, en un juicio concluyente, no dispone nada; tratándose, pues, de una pretensión a la que el Derecho no proporciona respaldo alguno, la respuesta de Eugenio es que el juez tiene sólo el deber genérico de fallar —y de construir 
para fundamentar el fallo una regla general en la que subsumir el caso individual — pero no tiene ningún deber específico, ni el de acoger la pretensión ni, como parecería natural, el de rechazarla. De acuerdo con Eugenio, cumple con su deber tanto si condena al demandado como si rechaza la pretensión contenida en la demanda. El Derecho le impone sólo la obligación genérica de fallar y no le proporciona guía alguna para optar por alguno de los sentidos posibles del fallo: opción que es, así, enteramente discrecional para el juez. Esto, resulta, desde luego, verdaderamente sorprendente. Como dice muy gráficamente J. C. BAYÓN, «sostener que cuando alguien pretende hacer valer un Derecho que (por hipótesis) no tiene el ordenamiento deja al juez en posición de decidir discrecionalmente si acoge o no semejante pretensión tiene que ser, en mi opinión, el producto de algún serio malentendido» ${ }^{10}$. Yo estoy enteramente de acuerdo con BAYÓN, pero me gustaría tratar de identificar, hasta donde sea posible, dónde se encuentran las raíces de un malentendido tan llamativo. Y me parece que las raíces del malentendido vienen a encontrarse en lo siguiente: Eugenio sostiene que tanto la sentencia de aceptación de la pretensión contenida en la demanda como la de rechazo de la misma expresan normas individuales. Pero esto no es, a mi juicio, así: la parte dispositiva de la sentencia de aceptación consta, desde luego, de una norma individual que ordena al demandado que realice la pretensión del demandante (o, eventualmente, que le indemnice por no haberla realizado); pero no puede decirse otro tanto de la sentencia de rechazo: aquí el juez no dicta ninguna norma individual, sino que más bien expresa su rechazo al dictado de norma individual alguna, sobre la base de que en el Derecho no se contiene ninguna base para tal dictado, ninguna base para la alteración de la situación normativa del demandado. Pues bien: de la idea de que tanto la sentencia de aceptación como la de rechazo contienen normas individuales, BULYGIN infiere la necesidad, en ambos casos, de una norma general en que fundarlas. Pero en la sentencia de rechazo no se contiene, como acabamos de ver, norma individual alguna.

Alguien podría, sin duda, dar una ulterior vuelta de tuerca y, tras conceder que la sentencia de rechazo no contiene ninguna norma individual, argumentar, sin embargo, que el acto de dictar la sentencia de rechazo, el acto mediante el cual el juez expresa su negativa a dictar norma alguna, requiere también, como todos los actos de los jueces, ser fundamentado en una norma general. Quien así argumentara tendría, indudablemente, razón. Pero, a partir de ahí, podría razonarse que, dado que — por hipótesis- no hay norma en la que subsumir el caso que se somete al juez, el juez ha de construir (discrecionalmente) esta norma para poder fundamentar una solución para el caso. Volveríamos, así, a la posición de BuLYGIN. El razonamiento precedente contiene, sin embargo, una falacia muy obvia. Y es que da por supuesto aquello que habría de demostrar: es decir, que la sentencia de rechazo contiene una solución al caso que se somete al juez. Pero — como he venido señalando— esto no es así. La sentencia de rechazo expresa más bien la negativa del juez a dictar una norma individual relativa al caso que se le somete: por la mera razón de que el ordenamiento no le proporciona base para el dictado de tal norma.

Por lo demás, el que no haya norma general en la que subsumir el caso que se somete al juez, no debe hacernos olvidar que el juez sí puede justificar su decisión,

10 BAYÓN, cit., 39. 
porque sí hay norma general en la que subsumir el caso del juez al que se somete un caso respecto del cual no hay norma general en la que subsumirlo: en un caso así —en el que se somete al juez una pretensión sin ningún respaldo en el ordenamiento- el juez debe rechazar la demanda, porque está prohibido para el juez acoger demandas sin respaldo en el ordenamiento. La existencia de esta norma prohibitiva es, desde luego, como probablemente le gustaría recordar a Eugenio, una cuestión contingente. Pero tal carácter contingente no suministra el menor apoyo a su posición. Porque, aunque contingente y no necesaria, una norma así existe en todos los sistemas jurídicos de nuestro horizonte cultural. Y existe en todos ellos porque, dictada o no, en todos ellos existe como norma aceptada, esto es, aceptada como un patrón común y público de decisiones judiciales correctas, cuya inobservancia da lugar a críticas que se consideran, sin más, justificadas. El que E. BuLYGin no tenga esto en cuenta vuelve a hacernos ver los efectos deletéreos que, sobre su teoría del Derecho, produce su insistencia en no tomar en consideración las creencias y actitudes compartidas en la comunidad jurídica.

\section{5.}

En trabajos dedicados a examinar las posiciones de E. BulYgin en torno a estas cuestiones, J. C. BAYÓN y M. ATIENZA ${ }^{11}$ manifiestan encontrarse mucho más próximos a mis tesis que a las de Eugenio. Así, AtiENZA escribe que «mi opinión es coincidente con, o muy parecida a, la de J. RUIZ MANERO» ${ }^{12}$, y BAYÓN indica que «mis opiniones, como se podrá apreciar con facilidad, son en gran medida deudoras de las que en aquella ocasión expusieron [...] ATRIA y RuIZ MANERO» ${ }^{13}$. Ello no obstante, tanto ATIENZA como BAYÓN me formulan críticas que, aunque orientadas en sentido opuesto, tienen como elemento común el que yo no llegue a decir con claridad que las cosas son, exactamente, como cada uno de ellos piensa que son. Así, ATIENZA me reprocha que mis definiciones de laguna axiológica y de laguna normativa «dan a entender que las lagunas sólo existirían en relación con las reglas» y que me ha faltado «sostener con rotundidad que no existen lagunas (o, en todo caso, de existir, sería un fenómeno absolutamente excepcional) en el Derecho adecuadamente entendido» ${ }^{14}$, esto es, entendido como suma de reglas y principios. La crítica de BAYÓN, por su parte, va en el sentido justamente inverso: lo que me ha faltado es decir con claridad si «en el nivel de las calificaciones normativas concluyentes o definitivas [esto es, a las que resultan tras haber atendido al balance, en relación con el caso, entre los principios relevantes del sistema] podría o no haber lagunas»; a juicio de BAYÓN, no se ve por qué no podría haberlas, pues «no creo — escribe- que pueda descartarse la posibilidad de que nuestras convenciones resulten insuficientes para determinar unívocamente en un caso qué es lo que resulta del balance entre los principios relevantes del sistema» ${ }^{15}$. Pues bien: mi posición, a este respecto, se encuentra en un punto que, si interpretamos las posiciones

${ }^{11}$ J. C. BAYÓN, op. cit.; M. ATIEnZA, «Sobre "Creación judicial del Derecho" de Eugenio Bulygin», en

E. Bulygin, M. Atienza y J. C. BAyón, Problemas lógicos en la teoría y la práctica del Derecho, cit.

12 ATIENZA, op. cit., 109.

13 BAYÓN, op. cit., 41. BAYÓN hace referencia a los textos contenidos en Lagunas en el Derecho, cit.

14 ATIENZA, op. cit., 116.

15 BAYÓN, op. cit., $44-45$ y 59. 
de ATIENZA y BAYÓN en el sentido de que uno niega lo que afirma el otro, no parece poder existir: en un punto intermedio entre ambos. Pero me parece que si interpretamos que ATIENZA y BAYÓN no niegan cada uno de ellos lo que afirma el otro, sino que uno y otro expresan su posición de una forma incompleta, bien pudiera ser que ambos concordaran en este punto aparentemente intermedio. De ser esto así, las diferencias que ellos mantienen entre sí, y cada uno de ellos conmigo, no serían de sustancia, sino simplemente de presentación y de énfasis. Pues bien, yendo ya al punto: a mi juicio, está presente en el razonamiento jurídico, como idea regulativa, que en el nivel de las calificaciones definitivas o concluyentes no hay lagunas, es decir, que es siempre posible determinar qué es lo que, todos los factores considerados, exige el Derecho; pero, naturalmente, nada garantiza la realizabilidad, en todos los casos, de tal idea regulativa. Pero tampoco hay nada que nos posibilite determinar a priori dónde está el límite de esa misma realizabilidad. 